DOI: 10.22616/REEP.2019.023

\title{
Factors Affecting the Acquisition of Playing the Metallophone in Music Lessons
}

\author{
Ligita Stramkale Dr. paed. \\ University of Latvia, Latvia \\ ligita.stramkale@lu.lv
}

\begin{abstract}
This paper analyses the factors affecting the acquisition of metallophone in primary school music lessons. The aim of the study is to determine the factors that affect the primary school student's performance while playing the metallophone in the classroom and to identify the factors that might be subject to change in case of repeating the performance. To achieve this aim, previous studies which focused on the impact of playing musical instruments on the students' musical, general and intellectual development have been analysed, and an empirical study on the factor affecting the acquisition of playing the metallophone was carried out. The study took place in two general education schools located in different Latvian cities during the period from March 2018 to May 2018, with a sample of 105 students $(\mathrm{N}=105)$ in the 3rd-grade. In order to identify the factors that might affect the primary school student while playing the metallophone, each student had to perform two exercises on the metallophone. After each exercise, the student was asked to complete a self-assessment questionnaire. The study identified four key factors determining the acquisition of metallophone, which are reflected in this paper as study dimensions: initiative, self-confidence, self-control, and achievement orientation. The study found that none of the factors that affect the acquisition of metallophone was at a low level. The students' achievement orientation was at a high level, which means that the students were interested in using metallophone to play both exercises. The students have assessed the self-control dimension at a middle level, which means that the self-control skills of the 3rd-grade students still need to be improved by encouraging them to continue practising on the musical instrument. Repeating the same exercise on the metallophone has shown that the students examine the correctness of their performance, are more restrained and more confident that they will achieve the goal. The study result provides an opportunity to better understand the impact of the initiative, self-confidence, self-control, and achievement orientation on the acquisition of playing the metallophone in primary school.
\end{abstract}

Keywords: play the metallophone, music lesson, a primary school student, school education.

\section{Introduction}

Playing musical instruments is one of the musical activities offering for primary school students in the music lesson. Teaching students to play complex, classical musical instruments in general education school could be quite difficult, because individual access for each child is needed, and it takes a lot of time to learn the musical instruments' playing techniques. A study conducted by J. Davidson, R. Faulkner, and G. McPherson emphasize that playing a musical instrument requires the students to have musical abilities, which can be improved "based on developing a range of complex and interactive cognitive, perceptual and action processes" (Davidson, Faulkner, McPherson, 2009, 1026). To ensure that playing musical instruments will not cause any difficulties for the primary school students, it is recommended to realize that on the basis of Carl Orff's musical education system. The Orff approach provides a pedagogical model to make it easier to acquire special instruments for an elementary musician - metallophone, xylophone, bells, triangles, as well as wind and percussion instruments. In music lesson, the students play a variety of percussive musical instruments, which are used to produce sound without an identifiable pitch or sound with identifiable pitch. It is more difficult for students to play on instruments that have definite pitch because in this case, it is necessary to play not only the rhythm precisely but also to play the correct sound. All musical instruments (including metallophone) can be played by primary school students regardless of the degree of their musical training, because, according to A. Long, the most important thing in the Orff approach is to promote creativity and to highlight the student's individual achievement (Long, 2013).

No doubt, playing musical instruments develops the student's musical abilities, but it is also important for developing the general abilities of the primary school age children. Several studies have been conducted on the relationship between playing musical instruments and general abilities. For example, K. Zalar, U. Kordes and B. Sicherl Kafol have studied the possibilities of using musical instruments in improving the social competences of primary school children. In the study, the playing of musical instruments took 
place in groups, which made it possible to conclude that mutual communication in acquiring musical language is more important than the acquisition of the musical instruments' playing techniques (Zalar, Kordes, Sicherl Kafol, 2015). The social interaction and communication skills as a result of playing the musical instruments are highlighted in a study conducted by B. Eren and G. Gül on the integration of Romani children into the education system. It is emphasized that the musician is an integral part of Romani's life therefore it is able to encourage Romani children to attend school (Eren, Gül, 2017). Meanwhile, D. Rose, A.J. Bartoli and P. Heaton carried out an experiment that compared two groups of students aged from seven to nine. One group of students played the musical instruments within the lesson hours provided for in the curriculum, but the other group played the musical instruments for more hours than the curriculum intended. The result showed that the group in which the students spent more hours playing musical instruments provides the opportunity not only to improve the students' musical abilities but also to refine their memory and psychomotor skills (Rose, Bartoli, Heaton, 2015). All forms of the musical activities, including play a musical instrument, develop the neuronal communication between the left and right brain hemispheres (Stoklosa, 2016), promote tolerance, creativity and discipline (Velikova, 2015), as well as improve children's cognitive skills, and encourage them to embrace being open-minded with more ambitious (Hillea, Schuppa, 2013). Playing musical instruments in the classroom influences students' learning achievement in other school subjects. For example, play a musical instrument promotes the acquisition of mathematics (Tezer, Cumhur, Hürsen, 2016) and languages (Lee, Lin, 2015).

Playing musical instruments is also an integral part of special education. Several studies have been conducted on the impact of playing musical instruments on the development of motor and cognitive skills of a child with special needs. The studies provide a deeper understanding of how a child with learning disabilities and behavioural disorders can benefit from playing musical instruments. For example, a study conducted by D. Rose, A.J. Bartoli and P. Heaton found that an eight-year-old boy diagnosed with autism spectrum disorder was able to play notes, improvise and be motivated to work, after playing musical instruments for one year. The only difficulty was to remember the note values (Rose, Bartoli, Heaton, 2018).

The aim of the study is to determine the factors that affect the primary school student's performance while playing the metallophone in the classroom, as well as to identify the factors that might be subject to change in case of repeating the performance.

\section{Methodology}

The participants were $105(\mathrm{~N}=105)$ primary school students in grade 3 . The study was conducted within the framework of the music lesson and took place in two X-town general education schools from March 2018 to May 2018.

The following research questions will be answered by the study:

- What factors affect the 3rd-grade students' acquisition of playing the metallophone?

- Which of the factors affecting the acquisition of playing the metallophone are subject to change in case of repeating the exercise?

To answer the questions raised in the study, the 3rd-grade students were given two exercises to be played on the metallophone. In the first exercise, each student had to play metro-rhythmically on the metallophone each measure of the first note for the Latvian folk song "Slauk' māmiña istabinuu" (Mama sweeps the room). Each student performed the following sequence of notes: do, sol, do', sol, sol, sol, sol, do, corresponding to one of the C-major three sounds. The second exercise, which was performed after a week, maintained the features of the previous exercise and included new requirements. Just like in the first exercise, the students had to play metro-rhythmically on the metallophone each measure of the first note for the Latvian folk song "Āvu, āvu baltas kājas" (I put on shoes and white stockings). Only in this time, playing the metallophone was not limited with the C-major three sounds, but each student had to perform metro-rhythmically the following sequence of notes: fa, mi, la, sol, la, sol, fa, fa.

After the first and the second exercise, the students had to complete a self-assessment questionnaire to identify the factors affecting the acquisition of playing the metallophone. The questionnaire consisted of 20 statements that should be assessed by each student using a 4-point Likert scale. The time to complete the questionnaire was not limited and all the responses collected were anonymous. For data processing, the response variants were recoded into digits: 4 - agree, 3 - partially agree, 2 - partially 
disagree and 1 - disagree. The 4-point Likert scale was converted to three levels where the arithmetic mean from 1 to 2 corresponds to a low level, from 2.01 to 3.00 corresponds to a middle level and from 3.01 to 4 corresponds to a high level.

The Cronbach's Alpha coefficient was calculated to determine the internal consistency reliability and the validity of the questionnaire statements. The factor analysis was used to identify the structure of the relationship between the statements and to determine the number of factors to be extracted. As a result of the factor analysis, the study identified four complex factors affecting the acquisition of playing the metallophone, which are reflected in this paper as study dimensions. The first dimension determined the students' initiative while performing the given exercise. The second dimension examined the students' self-confidence while playing the metallophone. The third dimension identified the students' self-control in using the metallophone. The fourth dimension, in turn, determined the students' achievement orientation in the process of acquiring the metallophone. Each study dimension is characterized by five statements.

The Bivariate (Pearson) correlation analysis was used to examine the reliability of the responses. The correlation coefficient has statistically significant sigma of 0.01 and 0.05 . The arithmetic mean $(\mathrm{M})$, the standard deviation (SD), the standard deviation error (SE) and the median (ME) were calculated for each statement. The arithmetic mean (M) was used because there is a directly proportional relationship between the variables included in the study. The standard deviation (SD) confirms the typicality of the arithmetic mean and indicates the level of variation, which in turn allows the study to compare and generalise the results obtained, as well as to determine the benefits of one variable in relation to another. The median (ME) describes the significance of the variable, and comparing it with the arithmetic mean (M) determines whether the data distribution in the study is symmetric or asymmetric.

In order to determine which of the factors that affect the acquisition of playing the metallophone could be subject to change in the case of repeating the exercise, the ANOVA was used. The Statistical Package for Social Science (SPSS) version 22 was used to analyse the collected data.

\section{Results and Discussion}

The internal consistency reliability and validity of the study data is sufficiently high $(\mathrm{a}=.817)$, which gives an opportunity to analyse each one of the study dimensions. The lowest mean score for one of the statements was $\mathrm{M}=2.20$ and the highest mean score was $\mathrm{M}=3.83$, which allowed the study to talk only about a middle or high level of the factors affecting the acquisition of playing the metallophone.

The initiative is one of the key factors affecting the acquisition of playing the metallophone. Table 1 shows five statements describing the student's initiative in the process of acquiring the metallophone.

Table 1

The student' initiative during the acquisition of playing the metallophone

\begin{tabular}{|l|l|r|r|r|c|}
\hline \multicolumn{2}{|c|}{ Statements } & M & SD & \multicolumn{1}{c|}{ SE } & ME \\
\hline 1. & I performed the exercise relentlessly & 3.20 & .892 & .087 & 3.00 \\
\hline 2. & I practised it over and over again & 3.58 & .793 & .077 & 4.00 \\
\hline 3. & I started the exercise at once & 3.56 & .897 & .087 & 4.00 \\
\hline 4. & I solved the problem encountered & 2.69 & 1.279 & .124 & 3.00 \\
\hline 5. & I wanted to reach my goal & 3.80 & .641 & .062 & 3.00 \\
\hline
\end{tabular}

The initiative is an introductory act or steps to begin something, it helps the student to reach the goal, to continue practising on a musical instrument and to be able to tackle and solve the problems encountered while playing an instrument. The initiative is characterized by the fact that the student starts performing the exercise immediately, not after a period of time.

The students assessed all the statements that characterize their initiative during the acquisition process of playing the metallophone at a high level except one of the statements that determines whether the students have tried to solve the problems that have been arisen while they performing the exercise. This statement assessed at a middle level. Almost all students agree that they wanted to reach their goal $(\mathrm{M}=3.80$; $\mathrm{SD}=.641)$, began to perform both exercises without unnecessary delay $(\mathrm{M}=3.56 ; \mathrm{SD}=.897)$ and continued to practice on the metallophone over and over again $(\mathrm{M}=3.58 ; \mathrm{SD}=.793)$. The study found that the 
statement "I wanted to reach the goal" has not got a uniform distribution of the collected data. This is proved by the difference between the arithmetic mean $(\mathrm{M}=3.80)$ and the median $(\mathrm{ME}=3.00)$. This means that among the group of the respondents were students, who had a very strong willingness to play the both given exercises correctly, but the majority of them were not sufficiently motivated to achieve the goal. If the student is motivated to achieve the goal, then he uses the time allocated for performing the exercises effectively ( $\mathrm{r}=0.493 ; \mathrm{p}<0.01)$, wants to complete the exercise well $(\mathrm{r}=0.460 ; \mathrm{p}<0.01)$, is interested in the exercises $(\mathrm{r}=0.339 ; \mathrm{p}<0.01)$, focuses only on performing the exercises and does not deal with other things $(\mathrm{r}=0.260 ; \mathrm{p}<0.01)$ and is able to practice on the metallophone over and over again $(\mathrm{r}=0.325 ; \mathrm{p}<0.01)$. To be motivated to play on the metallophone and at the same time to achieve the goal, the student needs to be certain about his abilities. $(\mathrm{r}=0.237 ; \mathrm{p}<0.05)$.

Most students partially agree or even partially disagree with the statement that they have tried to solve the problems encountered during playing the metallophone $(\mathrm{M}=2.69 ; \mathrm{SD}=1.279)$. To enable the students to deal with the problems until they solve it, it is important not only having the needed knowledge and skills to solve this problem, but also the initiative and the ability to act at a concrete situation. The initiative is expressed through the student's willingness to do more than it is required to perform the exercise. Solving the problems that were encountered while playing the metallophone is associated with the persistence $(\mathrm{r}=0.264 ; \mathrm{p}<0.01)$, and it is also essential that the given exercise should not be difficult for the student $(\mathrm{r}=0.341 ; \mathrm{p}<0.01)$.

The initiative could be stimulated by the joy of playing musical instrument therefore a suitable environment should be created in the classroom in order to provide the opportunity for each student, according to their individual abilities, to play a musical instrument with pleasure. Some researchers believe that not only the environment but also gender determines whether the student will choose to play one or another musical instrument. A study conducted by E.R. Wrape, A.L. Dittloff and J.L. Callahan found that gender stereotypes regarding the choice to play a musical instrument are still current issue that music teachers often face (Wrape, Dittloff, Callahan, 2016). It is not strange because it is considered that small children with very little experience have already their own opinion about which musical instrument is more suitable for women and which for men. N. Marshall and K. Shibazaki have come to the conclusion that the sound and visual image generated by the musical instrument have a strong association with the gender which in turn make a big impact on young children aged 3-4 (Marshall, Shibazaki, 2013). In addition, a study by J. Byo on which musical instruments the children usually choose to play in the third grade, concluded that the choice is determined by how the teacher introduces the musical instrument to the young children for the first time (Byo, 1991).

The second dimension determined the students' self-confidence while playing the metallophone. The opposite of self-confidence is unsureness. Self-confidence is a belief that the exercise will be performed successfully. Self-confidence is about knowing your own abilities. The Russian researcher I. M. Feygenberg thinks that self-confidence is associated with the level of competence (Feygenberg, 2014). Table 2 shows the statements that describe the students' self-confidence during the acquisition of playing the metallophone.

Table 2

The students' self-confidence during the acquisition of playing the metallophone

\begin{tabular}{|l|l|l|l|l|l|}
\hline \multicolumn{2}{|c|}{ Statements } & \multicolumn{1}{|c|}{ M } & \multicolumn{1}{c|}{ SD } & \multicolumn{1}{c|}{ SE } & ME \\
\hline 1. & I was sure that I was going to succeed & 3.29 & .960 & .093 & 4.00 \\
\hline 2. & The exercise was not difficult & 2.60 & 1.156 & .112 & 3.00 \\
\hline 3. & I learned from the others & 2.81 & 1.238 & .120 & 3.00 \\
\hline 4. & I performed the exercise convincingly & 3.14 & .994 & .097 & 3.00 \\
\hline 5. & If I failed, then it was my own fault & 3.56 & .911 & .089 & 4.00 \\
\hline
\end{tabular}

The students assessed three statements that describing their self-confidence at a high level and two statements at a middle level (table 2). Most students agree that they were sure about performing the exercise correctly $(\mathrm{M}=3.29 ; \mathrm{SD}=.960)$. The study results give an opportunity to conclude that the statement "I was sure that I was going to succeed" does not have a uniform data distribution because the arithmetic mean $(\mathrm{M}=3.29)$ is lower than the median $(\mathrm{ME}=4.00)$. This means that part of students has a low confidence 
that they will be able to perform the exercise on the metallophone correctly. The student who is confident that he will perform the exercise successfully uses the time allocated for performing the exercise effectively $(r=0.255 ; p<0.01)$, checks the correctness of the performance $(r=0.288 ; p<0.01)$ and focuses only on performing the current exercise $(\mathrm{r}=0.399 ; \mathrm{p}<0.01)$. The students are sure that they will succeed in completing the exercise if it matches their level of ability $(\mathrm{r}=0.313 ; \mathrm{p}<0.01)$. The confidence that the exercise can be performed correctly provides a peace of mind for the child $(r=0.287 ; p<0.01)$ and helps him to stay calm if problems or difficult situations have been arisen $(r=0.368 ; \mathrm{p}<0.01)$.

The majority of students partially agree or partially disagree that the exercises they had to play on the metallophone were not difficult for them. The students felt that the exercise was difficult for them to complete. At the same time, learning from other classmates as one of the ways to overcome the difficulties have been used by relatively few students $(\mathrm{M}=2.81 ; \mathrm{SD}=1.238)$. If the exercise is not difficult for the student, then he begins to do it immediately $(\mathrm{r}=0.302 ; \mathrm{p}<0.01)$, performs it relentlessly $(\mathrm{r}=0.263$; $\mathrm{p}<0.01)$, is sure that he will succeed $(\mathrm{r}=0.313 ; \mathrm{p}<0.01)$, is able to check the correctness of the performance $(\mathrm{r}=0.363 ; \mathrm{p}<0.01)$, wants to perform the exercise correctly $(\mathrm{r}=0.300 ; \mathrm{p}<0.01)$ and is interested in solving the problems that have arisen $(\mathrm{r}=0.341 ; \mathrm{p}<0.01)$.

Confident people are characterized by taking responsibility for their failures and mistakes. Nearly all the students agree with the statement that "if I failed, then it was my own fault" $(\mathrm{M}=3.56$; $\mathrm{SD}=.911)$. The students take responsibility for his failures or mistakes if he is interested in what he is doing $(\mathrm{r}=0.258 ; \mathrm{p}<0.01)$.

The third study dimension identified the students' self-control in the acquisition process of playing the metallophone. Self-control is essential for the student to control his or her emotions, and to prevent a flood of negative feelings or destructive behaviour if a concrete activity is failed. Table 3 shows five statements that describe the students' self-control during the acquisition of playing the metallophone.

Table 3

The students' self-control during the acquisition of playing the metallophone

\begin{tabular}{|l|l|c|c|c|c|}
\hline \multicolumn{2}{|c|}{ Statements } & M & SD & SE & ME \\
\hline 1. & I did not care & 2.21 & 1.270 & .124 & 3.00 \\
\hline 2. & I did not act unacceptably & 2.91 & 1.286 & .125 & 4.00 \\
\hline 3. & I did not lose control & 2.92 & 1.268 & .123 & 4.00 \\
\hline 4. & I was calm & 2.71 & 1.276 & .124 & 3.00 \\
\hline 5. & I did not disturb the others & 3.42 & 1.054 & .102 & 4.00 \\
\hline
\end{tabular}

Self-control helps to maintain adequate work performance in a stressful situation. Self-control is characterized by the ability to stay calm under pressure and to maintain a sense of control, as well as preventing any unacceptable behaviour in the class which could disturb the other classmates while performing the given exercises. Four statements of five that indicates the level of self-control during the acquisition of playing the metallophone have been assessed by the students at a middle level, and only one statement that determined whether the students disturb the other classmates while performing the exercise has been assessed at a high level.

Most students believed that they were worried while playing on the metallophone $(\mathrm{M}=2.21 ; \mathrm{SD}=1.27)$. The worry was about losing their control $(\mathrm{r}=0.380 ; \mathrm{p}<0.01)$, as a result of that it was difficult for students to maintain peace as well $(\mathrm{r}=0.650 ; \mathrm{p}<0.01)$. Losing control is not always mean that the students act in an unacceptable manner dealing with a concrete situation $(\mathrm{M}=2.91 ; \mathrm{SD}=1.286)$. However, the study found that the arithmetic mean score was significantly lower than the median score $(M=2.91$.; $\mathrm{ME}=4.00$ ), which gives the opportunity to conclude that on the one hand, there were some students who reacted clearly inadequate to the stressful situation created during playing the metallophone, but on the other hand, there were students who responded adequately, even if they were worried. Losing control is associated with worry $(\mathrm{r}=0.380 ; \mathrm{p}<0.01)$ and is largely described by the statements included in the selfconfidence dimension. Namely, the students do not lose their control if they have the confidence that they will able to perform the exercise correctly $(\mathrm{r}=0.287 ; \mathrm{p}<0.01)$, as well as if the exercise is not difficult for them $(\mathrm{r}=0.386 ; \mathrm{p}<0.01)$. The students will be calm if they are interested in the activity they dealing with in the classroom $(r=0.260 ; p<0.01)$. 
The majority of the students agree that they do not disturb the other classmates during playing the metallophone $(\mathrm{M}=3.42 ; \mathrm{SE}=1.054)$. The students will not disturb each other, if they are interested in the given exercise $(r=0.260 ; p<0.01)$, are relentlessly $(r=0.297 ; p<0.01)$ and begin to perform the exercise at once $(\mathrm{r}=0.261 ; \mathrm{p}<0.01)$.

J.V. Davidson, S.E. Pitts and J. Salgado-Correia emphasize that the learning process of playing a musical instrument is individual. Even the student who does not achieve a high level of playing a musical instrument should spend a lot of time to learn how to play individually. That requires the student to have a high level of self-sufficiency and ability to be self-reflective (Davidson, Pitts, Salgado-Correia, 2001).

The fourth study dimension determined the students' achievement orientation during the process of acquiring the metallophone. The achievement orientation can be expressed as an interest in doing something well. The achievement-oriented student uses the time allocated for performing the exercise effectively, examines the quality of the performance and focuses only on performing the exercise. Table 4 shows the students' achievement orientation in acquiring the metallophone.

Table 4

The students' achievement orientation during the acquisition of playing the metallophone

\begin{tabular}{|l|l|c|c|c|c|}
\hline \multicolumn{2}{|c|}{ Statements } & M & SD & SE & ME \\
\hline 1. & I used the time allocated for the exercise effectively & 3.54 & .832 & .0812 & 4.00 \\
\hline 2. & I checked the correctness of the exercise & 3.37 & .922 & .090 & 4.00 \\
\hline 3. & I wanted to perform the exercise well & 3.83 & .573 & .056 & 4.00 \\
\hline 4. & I did the exercise with interest & 3.33 & 1.015 & .099 & 4.00 \\
\hline 5. & I focused only on performing the exercise & 3.52 & .748 & .073 & 4.00 \\
\hline
\end{tabular}

Five statements that describe the students' achievement orientation in the acquisition of playing the metallophone have been assessed at a high level. The students' achievement orientation is closely related to their initiative. Almost all students fully agree that they used the time allocated for performing the exercise effectively $(\mathrm{M}=3.54 ; \mathrm{SD}=.832)$ and wanted to complete the exercise well $(\mathrm{M}=3.83 ; \mathrm{SE}=.573)$. If the students use the time allocated for the exercise effectively and want to perform it correctly, then they begin to perform it immediately without any hesitation $(\mathrm{r}=0.321 ; \mathrm{p}<0.01)$, do it relentlessly $(\mathrm{r}=0.344 ; \mathrm{p}<0.01)$, repeat it constantly $(\mathrm{r}=0.333 ; \mathrm{p}<0.01)$ and want to achieve the goal $(\mathrm{r}=0.493 ; \mathrm{p}<0.01)$. The student's willingness to check the correctness of the performance is related to the confidence of performing the given exercise on the metallophone successfully $(r=0.288 ; p<0.01)$. The majority of students agree or partially agree that the exercises on the metallophone were performed with interest $(\mathrm{M}=3.33 ; \mathrm{SD}=1.015)$. The students play the metallophone with interest if they want to learn to play well on it $(\mathrm{r}=0.407 ; \mathrm{p}<0.01)$, if they are motivated to reach their goal $(\mathrm{r}=0.339 ; \mathrm{p}<0.01)$ and if playing the metallophone does not cause any difficulties for them $(r=0.300 ; p<0.01)$. The student who is interested in playing the metallophone is calmer than the one who does not have any degree of interest to use the metallophone $(r=0.260 ; p<0.01)$, he is a lot more confident of what he is doing $(r=0.286 ; p<0.01)$ and does not disturb the other classmates while playing the metallophone $(r=0.260 ; p<0.01)$.

L.M. Spencer and S.M. Spencer note that a high level of achievement orientation may be also for children whose status and influence in the classroom are low (Spencer, Spencer, 1993). The role of a concrete student for the classmates determines his status and influence.

The second study question was to determine which of the factors affecting the acquisition of playing the metallophone are subject to change if repeating the performance is needed. The study found that in case of repeating the same exercise on the metallophone, the students were more likely to check the correctness of the performance $(\mathrm{F}=4.804$; sig. $=.031)$, they have got more control $(\mathrm{F}=5.083$; sig. $=.027)$ and they are more confident that the performance will be completed correctly ( $\mathrm{F}=4.550$; sig. $=.036$ ). Repeating a similar exercise on the metallophone is connected with three of the study dimensions: the achievement orientation, the self-confidence and the self-control. 


\section{Conclusions}

The study found that the acquisition of playing the metallophone is determined by several factors, firstly, the level of initiative the student was showing while playing the metallophone, secondly, whether the student is confident that he is going to succeed in acquiring the metallophone, thirdly, whether the student is able to control the quality of playing the metallophone and fourthly, whether the student is achievement-oriented.

The student's initiative is closely associated with the willingness to achieve the goals. At the same time, in order to accomplish the goal of acquiring the metallophone, the student must keep practising on this musical instrument relentlessly, should be able to deal with any problems or difficult situations and be motivated to start the given exercise immediately. The study found that the primary school students have insufficient skills and knowledge to deal with the problems that could arise while playing a musical instrument which in turn reduces their motivation to complete the exercise in good quality. The teachers need to focus on improving the students' ability to apply problem-solving skills when they faced difficult situations or problems while playing a musical instrument in the classroom. The problem solving usually involved the following steps: the students learn to generate potential solutions for their problem, evaluate the solutions presented and select the appropriate solution to improve the metallophone playing skills.

The student needs to be confident enough to be able to play the metallophone successfully. Selfconfidence is the assurance in your own abilities and knowledge. Playing the metallophone requires the students not only to have a sense of rhythm but also to be careful and be able to focus on the current activity. Therefore, it is important to understand how we can help the student evaluate his musical and general abilities. First of all, it is necessary to pay attention to the quality of the performance, which in turn provides the opportunity to recognize the children musical abilities and, at the same time, increases their self-confidence. Secondly, the children need to learn the way which helps them to concentrate in the classroom and to focus only on the current activity.

Self-control is also one of the factors affecting the quality of the acquisition of playing the metallophone. It is largely related not to competences but to a current situation. Self-control can be learned. In order to develop the self-control skills, the primary school students should acquire the skills to identify the goals to be reached precisely, as well as to build the strategies for monitoring and reflecting the achieved results. The student's self-control will be better if he plays the metallophone for personal reasons and if the playing gives him pleasure.

All the statements describing the achievement orientation have been assessed by the students at a high level. This means that the students wanted to perform both exercises on the metallophone in a good quality. The students who have not got any important role among their classmates could also want to perform the exercise well, focus only on the performance and use the time allocated for performing the exercise effectively.

\section{Bibliography}

1. Byo J. (1991). An Assessment of Musical Instrument Preferences of Third-Grade Children. Bulletin of the Council for Research in Music Education, 110, 21-32.

2. Davidson J., Faulkner R., McPherson G. (2009). Motivating musical learning. The Psychologist, 22 (12), 1026-1029.

3. Davidson J.W., Pitts S.E., Salgado-Correia J. (2001). Reconciling Technical and Expressive Elements in Musical Instrument Teaching: Working with Children. Journal of Aesthetic Education, 35 (3), 51-62.

4. Eren B., Gül G. (2017). The use of Orff based music activities for educational and therapeutic purposes with disadvantaged group of Romani children. Educational Research and Reviews, 12 (22), 1062-1073. Retrieved from https://files.eric.ed.gov/fulltext/EJ1161438.pdf

5. Feygenberg I.M. (2014). Uchimsja vsyu zhizn (Lifelong learning). Moskva: Smysl. (in Russian)

6. Hillea A., Schuppa J. (2013). How learning a musical instrument affects the development of Skills. Berlin: SOEP. Retrieved from https://www.diw.de/documents/publikationen/73/diw_01.c.429221.de/diw_sp0591.pdf

7. Lee L., Lin S. (2015). The Impact of Music Activities on Foreign Language, English Learning for Young Children. Journal of the European Teacher Education Network, 10, 13-23. 
8. Long A. (2013). Involve Me: Using the Orff Approach within the Elementary Classroom. Awards for Excellence in Student Research \& Creative Activity - Documents. 4. Retrieved from https://thekeep.eiu.edu/cgi/viewcontent.cgi?article=1003\&context=lib_awards_2013_docs

9. Marshall N., Shibazaki K. (2013). Gender associations for musical instruments in nursery children: the effect of sound and image. Music Education Research, 15 (4), 406-420.

10. Rose D., Bartoli A.J., Heaton P. (2015). A study of cognitive and behavioral transfer effects associated with children learning musical instruments for the first year over one academic year. The Psychology of Education Review, 39 (2), 54-70.

11. Rose D., Bartoli A.J., Heaton P. (2018). Learning a Musical Instrument Can Benefit a Child with Special Educational Needs. Psychomusicology: Music, Mind, and Brain, 28 (2), 71-81.

12. Spencer L.M., Spencer S.M. (1993). Competence at Work: models for superior performance. ( $1^{\text {st }}$ ed.). New York: Wiley\&Sons.

13. Stoklosa A.R. (2016). Instruments of Knowledge: Music and the Brain. The Review: A Journal of Undergraduate Student Research. 17 (12), Retrieved from

https://fisherpub.sjfc.edu/ur/vol17/iss1/12

14. Tezer M., Cumhur M., Hürsen E. (2016). The Spatial-Temporal Reasoning States of Children Who Play a Musical Instrument, Regarding the Mathematics Lesson: Teachers' Views. Journal of Mathematics, Science \& Technology Education, 12 (6), 1487-1498.

15. Velikova M. (2015). The importance of leisure time musical activities in children's education and development as established by reformers of the music pedagogy. Trakia Journal of Sciences, 13 (1), 480-486. Retrieved from http://tru.unisz.bg/tsj/Vol.\%2013,\%202015,\%20Supp1.\%201,\%20Series\%20Social\%20Sciences/PF/PF/Obra z\%20i\%20ped/M.Velikova.pdf

16. Wrape E.R., Dittloff A.L., Callahan J.L. (2016). Gender and Musical Instrument Stereotypes in Middle School Children: Have Trends Changed? Applications of Research in Music Education, 34 (3), 40-47.

17. Zalar K., Kordes U., Sicherl Kafol B. (2015). The Role of Children's Musical Instruments in Communication with Musical Language. Procedia - Social and Behavioral Sciences, 197, 13261334. 